\title{
Distinct Autophosphorylation Sites Sequentially Produce Autonomy and Inhibition of the Multifunctional $\mathrm{Ca}^{2+} /$ Calmodulin-Dependent Protein Kinase
}

\author{
Lillian L. Lou and Howard Schulman \\ Department of Pharmacology, Stanford University School of Medicine, Stanford, California 94305
}

The multifunctional $\mathrm{Ca}^{2+} /$ calmodulin-dependent protein kinase (multifunctional CaM kinase) may be an important mediator for neurotransmitters and hormones that utilize $\mathrm{Ca}^{2+}$ as a "second messenger." We examined the ability of autophosphorylation to convert the multifunctional CaM kinase to a $\mathrm{Ca}^{2+} /$ calmodulin-independent (autonomous) form to determine whether autophosphorylation is a mechanism for short- or long-term enhancement of $\mathrm{Ca}^{2+}$ action. As the kinase incorporates phosphate during continuous stimulation by $\mathrm{Ca}^{2+}$ /calmodulin, its ability to phosphorylate exogenous substrates becomes increasingly autonomous. Withdrawal of $\mathrm{Ca}^{2+}$ after a critical level of phosphate incorporation is reached leads to a "burst" or rapid increase in $\mathrm{Ca}^{2+}$-independent autophosphorylation. The "burst" of autophosphorylation is distinct from the initial $\mathrm{Ca}^{2+}$-dependent autophosphorylation, however, since it inhibits substrate phosphorylation. Both $\mathrm{Ca}^{2+}$-dependent and $\mathrm{Ca}^{2+}$-independent substrate phosphorylation are inhibited by this autonomous autophosphorylation. Thus, autophosphorylation has a dual role in modulating the activity of multifunctional CaM kinase. It initially enables the kinase to continue phosphorylating substrates after $\mathrm{Ca}^{2+}$ levels decline, but it eventually suppresses this autonomous activity. Tryptic phosphopeptide mapping demonstrates that appearance of phosphothreonine-containing peptides is common to several conditions used to generate an autonomous enzyme. Sequencing reveals the critical "autonomy" site to be threonine ${ }^{286}$. The inhibitory mode of autophosphorylation involves 3 additional phosphopeptides containing a serine and a threonine residue.

Intracellular $\mathrm{Ca}^{2+}$ serves as a second messenger mediating the effects of many neurotransmitters, growth factors, hormones, and other extracellular signals (Berridge and Irvine, 1984; Nishizuka, 1986). We and others have identified and characterized a

\footnotetext{
Received Mar. 7, 1988; revised July 7, 1988; accepted Nov. 7, 1988.

We wish to thank Dr. K. Tatemoto and Mr. G. Makk for invaluable assistance in phosphopeptide sequencing and Dr. Thomas Ingebritsen for providing us with generous supplies of phosphoprotein phosphatases. We thank Drs. Eric R. Kandel, James H. Schwartz, and Richard W. Tsien for their helpful comments on earlier drafts of this manuscript and Miriam Flock and Drs. Richard R. Roth and James P. Whitlock for reading this manuscript. This research was supported by Public Health Service Grant GM 30179 (H.S.) and a Public Health Service Postdoctoral Fellowship GM 10686 (L.L.).

Correspondence should be addressed to Howard Schulman, Department of Pharmacology, Stanford University School of Medicine, Stanford, CA 943055332.

Copyright (C) 1989 Society for Neuroscience $0270-6474 / 89 / 062020-13 \$ 02.00 / 0$
}

$\mathrm{Ca}^{2+} /$ calmodulin-dependent protein kinase in brain and other tissues that appears to mediate numerous effects of extracellular signals that elevate $\mathrm{Ca}^{2+}$ (reviewed in Stull et al., 1986; Edelman et al., 1987; Kennedy et al., 1987; Schulman, 1988; Schulman and Lou, 1989). We refer to this enzyme as the multifunctional $\mathrm{Ca}^{2+} /$ calmodulin-dependent protein kinase or simply as the multifunctional CaM kinase bccausc it differs from other $\mathrm{Ca}^{2+}$ / calmodulin-dependent kinases such as myosin light chain kinase (MLCK) and phosphorylase kinase, which have a more limited substrate specificity (Edelman et al., 1987). It is most prominent in brain, where it can be found as high as 1-2\% of total protein in several regions (Erondu and Kennedy, 1985). The multifunctional CaM kinase from the various sources appears to have nearly identical functional characteristics. The enzyme has been shown to phosphorylate synapsin I (Nestler and Greengard, 1982), tyrosine hydroxylase (Tachikawa et al., 1987; Griffith and Schulman, 1988), and pyruvate kinase (Connelly et al., 1987) in situ and to phosphorylate these proteins as well as microtubule-associated protein 2 (MAP-2), tau, glycogen synthase, myosin light chain, and phospholamban in vitro (reviewed in Schulman, 1988). In analogy with the cAMP-dependent protein kinase and protein kinase $\mathrm{C}$, the multifunctional $\mathrm{CaM} \mathrm{ki}$ nasc may be a major protein kinase orchestrating the effects of diverse extracellular signals.

The multifunctional CaM kinase from rat brain is composed of $\alpha$ and $\beta$ subunits with molecular weights of 54,111 and 60,333, respectively, based on molecular cloning (Bennett and Kennedy, 1987; Lin et al., 1987). The enzyme from rat forebrain is a decameric or dodecameric holoenzyme with a $3: 1$ or $4: 1$ ratio of $\alpha$ to $\beta$ subunits. The subunits are nearly identical in sequence and each contains a protein kinase domain and a calmodulinbinding domain. The additional amino acids found in the $\beta$ subunit reside in two "inserts" on the carboxy terminal side of the calmodulin-binding domain (Bulleit et al., 1988). The subunits also have nearly indistinguishable functional properties. Isozymes enriched with predominantly $\alpha$ subunits or with predominantly $\beta$ subunits have the same substrate specificity (McGuinness et al., 1983). Each subunit is capable of calmodulin binding and autophosphorylation independently (Kuret and Schulman, 1985).

A hallmark of any signal transduction system is the presence of several levels of regulation. It is not surprising, therefore, that an intracellular effector of $\mathrm{Ca}^{2+}$ such as the multifunctional $\mathrm{CaM}$ kinase is also highly regulated. The enzyme is tightly regulated by $\mathrm{Ca}^{2+} /$ calmodulin. Neither its self-phosphorylation (autophosphorylation) nor the phosphorylation of exogenous substrates (e.g., MAP-2 or synapsin I) occurs in the absence of either 
activator. Autophosphorylation leads to generation of a $\mathrm{Ca}^{2+} /$ calmodulin-independent (autonomous) kinase activity (Saitoh and Schwartz, 1983, 1985; Lai et al., 1986; Lou et al., 1986; Miller and Kennedy, 1986). The Aplysia counterpart of this kinase additionally undergoes translocation from a cytoskeletal to a soluble form upon autophosphorylation (Saitoh and Schwartz, 1985). The functional consequences of autophosphorylation can be modulated by the concentration of ATP as well as reaction temperature, thereby leading to apparently conflicting rcports in the literature. Extensive phosphorylation at low ATP $(<25 \mu \mathrm{M})$ leads to reduced autonomy and inhibition or inactivation of enzyme activity (Kuret and Schulman, 1985; Lou et al., 1986). This can be prevented by using more physiological levels of ATP ( $>200 \mu \mathrm{M}$; Lou et al., 1986) or by carrying out the reaction at $0^{\circ} \mathrm{C}$ (Lai et al., 1986), conditions that appear to stabilize the autonomous form. The complex regulation of the kinase and its critical dependence on reaction conditions is probably responsible for some of the apparent differences reported in the literature.

An intriguing role for the autophosphorylation of the neuronal kinase in information storage has been suggested (Saitoh and Schwartz, 1985; Miller and Kennedy, 1986) based on theoretical models (Crick, 1984; Lisman, 1985). In such a model, applied to the multifunctional CaM kinase, neuronal stimuli would elicit a brief rise in $\mathrm{Ca}^{2+}$ and thereby initiate autophosphorylation, which would continue autonomously once $\mathrm{Ca}^{2+}$ levels declined. The kinase would maintain itself in an autophosphorylated and activated state as long as autophosphorylation exceeded the rate of dephosphorylation (Lisman, 1985; Miller and Kennedy, 1986; Lisman and Goldring, 1988).

We sought to test the "memory" model by determining whether phosphorylation of substrates by the autophosphorylated kinase can be maintained without its normal stimulus, $\mathrm{Ca}^{2+}$. We show that the multifunctional $\mathrm{CaM}$ kinase, primed by a brief prephosphorylation, undergoes a "burst" of autonomous autophosphorylation upon removal of $\mathrm{Ca}^{2+}$. This $\mathrm{Ca}^{2+}$ calmodulin-independent autophosphorylation shuts off substrate phosphorylation. We characterize the phosphorylation sites that are responsible for generating a $\mathrm{Ca}^{2+} /$ calmodulin-independent protein kinase and those responsible for inhibiting it.

\section{Materials and Methods}

SDS electrophoresis reagents (other than acrylamide) were from BioRad Laboratories. $\left[\gamma^{-32} \mathrm{P}\right]$ ATP $(7000 \mathrm{Ci} / \mathrm{mmol})$ was purchased from ICN. All other chemicals were obtained from Sigma. Calmodulin was prepared as described (Schulman and Greengard, 1978). MAP-2 was purified from bovine brain cortical gray matter as described (Herzog and Weber, 1978; Lou et al., 1986). The multifunctional CaM kinase was purified from rat brain cytosol (specific activity of $0.3 \mu \mathrm{mol} / \mathrm{min} /$ $\mathrm{mg}$ in the MAP-2 phosphorylation assay) as described (Schulman, 1984).

Analysis and preparation of autophosphorylated kinase. Autophosphorylation was assayed in a reaction mixture that contained $130 \mathrm{ng}$ purified kinase in $50 \mathrm{~mm}$ Pipes pH 7.0, $10 \mathrm{~mm} \mathrm{MgCl}_{2} 500 \mu \mathrm{M} \mathrm{CaCl}_{2}$ (plus calcium) or $1 \mathrm{mM}$ EGTA (minus calcium), $5 \mu \mathrm{g} / \mathrm{ml}$ calmodulin, $0.1 \mathrm{mg} / \mathrm{ml}$ bovine serum albumin, and $500 \mu \mathrm{M}\left[\gamma^{-32} \mathrm{P}\right] A T P(0.5 \mathrm{Ci} /$ mmol) or unlabeled ATP as indicated, in a total volume of $100 \mu \mathrm{l}$. We found that $500 \mu \mathrm{M}$ is required to optimize for autophosphorylation of the kinase at $30^{\circ} \mathrm{C}$. For determination of ${ }^{32} \mathrm{P}$ incorporation, kinase subunits were separated by $8 \%$ SDS polyacrylamide gel electrophoresis and then analyzed by autoradiography as described (O'Farrell, 1975). Incorporation of ${ }^{32} \mathrm{P}$ was determined by excising the gel bands corresponding to the kinase subunits and quantifying Cerenkov radiation in a Beckman scintillation spectrometer as described (Schulman, 1984).

For experiments designed to assess the effect of autophosphorylation on kinase activity, purified kinase was added to a standard reaction mixture containing the indicated amounts of unlabeled ATP. This standard mixture was maintained at the specified temperature $\left(30^{\circ} \mathrm{C}\right.$ or $\left.0^{\circ} \mathrm{C}\right)$ for the indicated times and terminated by rapidly adding EDTA (20 mM final concentration). ATP or other reagents were then supplemented where needed to make their concentration in each sample equivalent, and the assay for MAP-2 kinase activity was performed immediately.

MAP-2 kinase assay. Activity of control or autophosphorylated kinase was determined by MAP-2 phosphorylation at a 1:40 dilution from the preincubation as described (Lou et al., 1986). The assay contained $1 \mu \mathrm{g}$ of purified MAP-2 and $20 \mu \mathrm{M}\left[\gamma^{-32} \mathrm{P}\right]$ ATP $(10 \mathrm{Ci} / \mathrm{mmol})$ in standard reaction mixtures. The 2 standard mixtures were used to assay $\mathrm{Ca}^{2+}$ stimulated and $\mathrm{Ca}^{2+}$-independent activitics of the enzyme and consisted of the following: $50 \mathrm{~mm}$ Pipes ( $\mathrm{pH} 7.0$ ), $10 \mathrm{mM} \mathrm{MgCl}_{2}$ and either 500 $\mu \mathrm{m} \mathrm{CaCl}_{2}$ and $5 \mu \mathrm{g} / \mathrm{ml}$ calmodulin (stimulated) or $200 \mu \mathrm{M}$ EGTA (unstimulated). MAP-2 phosphorylation was determined by counting Cerenkov radiation of excised gel bands as above.

Two-dimensional tryptic phosphopeptide mapping. Autophosphorylated kinase was prepared with $\left[\gamma^{-32} \mathrm{P}\right] \mathrm{ATP}$ and the subunits were separated on SDS polyacrylamide gels as described above. Protein was extracted from gel pieces and digested with $0.1 \mathrm{mg} / \mathrm{ml}$ bovine pancreatic trypsin (Sigma, type XI) as described (Beemon and Hunter, 1978). The digests were applied to $20 \times 20 \mathrm{~cm}$ plastic plates coated with silica gel 60 (E. Merck) and electrophoresed in formic acid:glacial acetic acid: water $(25: 78: 897, \mathrm{vol} / \mathrm{vol})$ at 2000 volts for $55 \mathrm{~min}$ in an apparatus designed by T. Hunter (The Salk Institute). The second dimension of separation was accomplished by thin layer chromatography in a solvent mixture consisting of n-butanol, pyridine, glacial acetic acid, and water $(20: 25: 5: 22, \mathrm{vol} / \mathrm{vol})$. Phosphopeptides were analyzed by autoradiography.

Phosphoamino acid analysis. Phosphopeptides were extracted from silica plates after separation in 2 dimensions. Carrier phosphoamino acid standards $(30 \mathrm{nmol}$ each of phosphoserine, phosphotyrosine, and phosphothreonine) were mixed with the radioactive phosphopeptides, and the mixtures were hydrolyzed in $6 \mathrm{~N} \mathrm{HCl}$ under $\mathrm{N}_{2}$ atmosphere. After $2 \mathrm{hr}$ at $110^{\circ} \mathrm{C}, \mathrm{HCl}$ was removed under reduced pressure, and the hydrolyzates were applied to silica plates and electrophoresed in pyridine:glacial acetic acid: water $(5: 25: 970, \mathrm{vol} / \mathrm{vol})$ as above. Carrier phosphoamino acids were detected by ninhydrin reaction and radioactive phosphoamino acids by autoradiography.

Identification of "autonomy" site. The multifunctional CaM kinasc $(6 \mu \mathrm{g})$ was autophosphorylated at $0^{\circ} \mathrm{C}$ for $5 \mathrm{~min}$ at $5 \mu \mathrm{M}$ ATP $(50 \mathrm{Ci} /$ mmol) to selectively label the "autonomy" site. The autophosphorylated $\alpha$ subunit was isolated as for tryptic digests and cleaved at $20^{\circ} \mathrm{C}$ (in the dark) with $8 \mathrm{mg} \mathrm{CNBr}$ in $400 \mu \mathrm{l} 70 \%$ formic acid. The major phosphopeptide was isolated as the included peak on Sephadex G-50 (60\% yield). This material contained exclusively phosphothreonine and eluted as a single peak on HPLC after reduction and alkylation with iodoacetamide; it was analyzed without further purification. The location of the phosphorylated residue in the CNBr fragment was determined essentially as described by Fiol et al. (1987). Sequencing was performed by a gas-phase sequencer (Applied Biosystems) by automated serial Edman degradation. Equal amounts of phosphopeptide $(9000 \mathrm{cpm})$ were applied to glass fiber sample filters; sequencing proceeded for the indicated cycles, at which point the radioactive material was extracted and the percentage released as ${ }^{32} \mathrm{Pi}$ was determined.

\section{Results}

We and others have shown that autophosphorylation of the multifunctional CaM kinase in the continuous presence of $\mathrm{Ca}^{2+} /$ calmodulin produces an autonomous kinase activity capable of $\mathrm{Ca}^{2+}$-independent phosphorylation of substrates (Saitoh and Schwartz, 1985; Lai et al., 1986; Lou et al., 1986; Miller and Kennedy, 1986; Schworer et al., 1986). Since neuronal stimuli generally involve only transient elevations of $\mathrm{Ca}^{2+}$, we reasoned that incubation of kinase in the presence of high and then low levels of $\mathrm{Ca}^{2+}$ would better reflect its in vivo exposure to $\mathrm{Ca}^{2+}$. We therefore examined the effects of sequential exposure of the kinase to high and low $\mathrm{Ca}^{2+}$ on 2 characterized activities of the kinase-phosphorylation of itself and phosphorylation of substrate proteins.

We began by analyzing the autophosphorylation in a 2 -step 

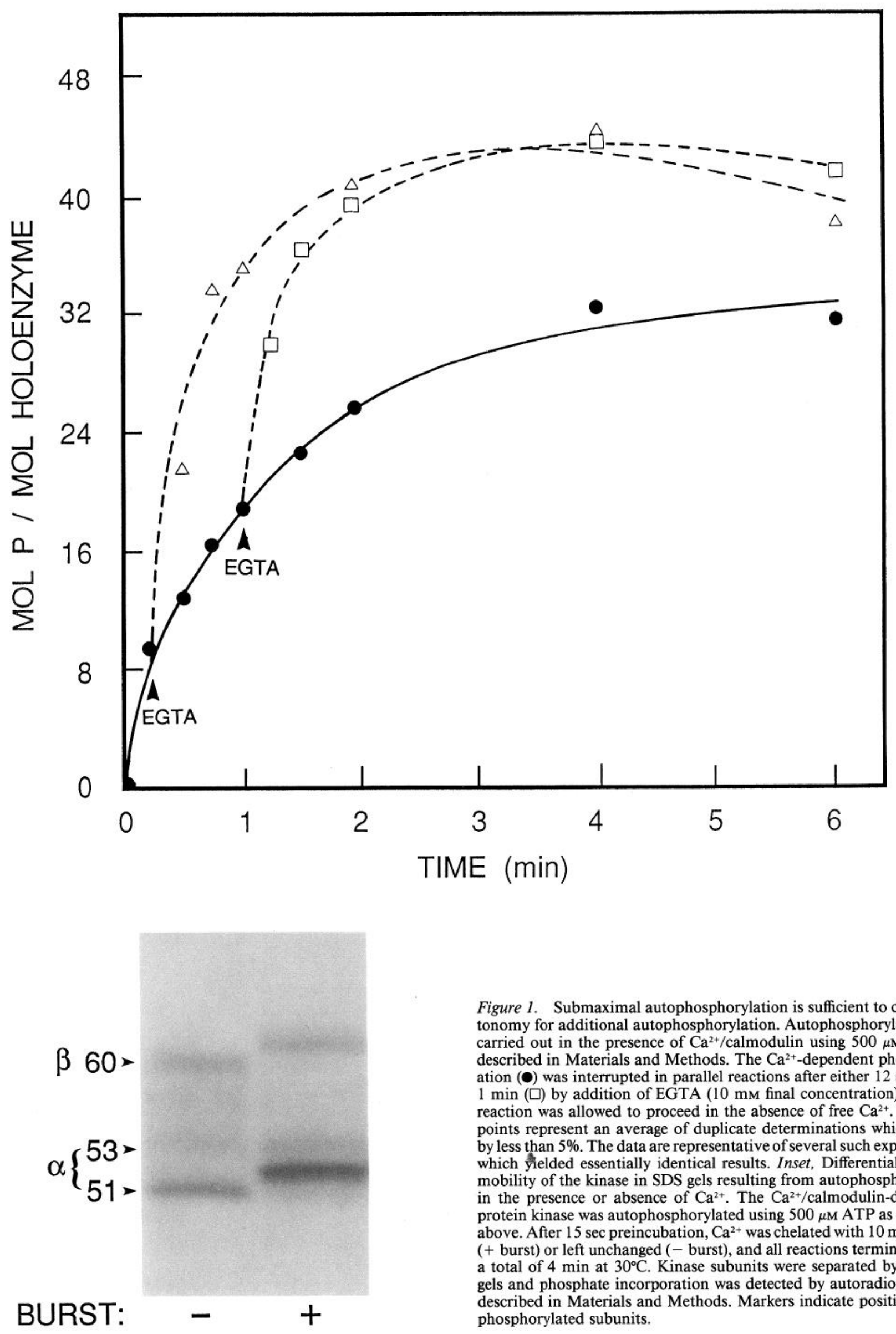

Figure 1. Submaximal autophosphorylation is sufficient to confer autonomy for additional autophosphorylation. Autophosphorylation was carried out in the presence of $\mathrm{Ca}^{2+} /$ calmodulin using $500 \mu \mathrm{M}$ ATP as described in Materials and Methods. The $\mathrm{Ca}^{2+}$-dependent phosphorylation $(\bullet)$ was interrupted in parallel reactions after either $12 \sec (\Delta)$ or $1 \mathrm{~min}(\square)$ by addition of EGTA (10 mm final concentration), and the reaction was allowed to proceed in the absence of free $\mathrm{Ca}^{2+}$. The data points represent an average of duplicate determinations which varied by less than $5 \%$. The data are representative of several such experiments, which yelded essentially identical results. Inset, Differential shifts in mobility of the kinase in SDS gels resulting from autophosphorylation in the presence or absence of $\mathrm{Ca}^{2+}$. The $\mathrm{Ca}^{2+} /$ calmodulin-dependent protein kinase was autophosphorylated using $500 \mu \mathrm{M}$ ATP as described above. After $15 \mathrm{sec}$ preincubation, $\mathrm{Ca}^{2+}$ was chelated with $10 \mathrm{~mm}$ EGTA (+ burst) or left unchanged ( - burst), and all reactions terminated after a total of $4 \mathrm{~min}$ at $30^{\circ} \mathrm{C}$. Kinase subunits were separated by $8 \%$ SDS gels and phosphate incorporation was detected by autoradiography as described in Materials and Methods. Markers indicate position of unphosphorylated subunits. 


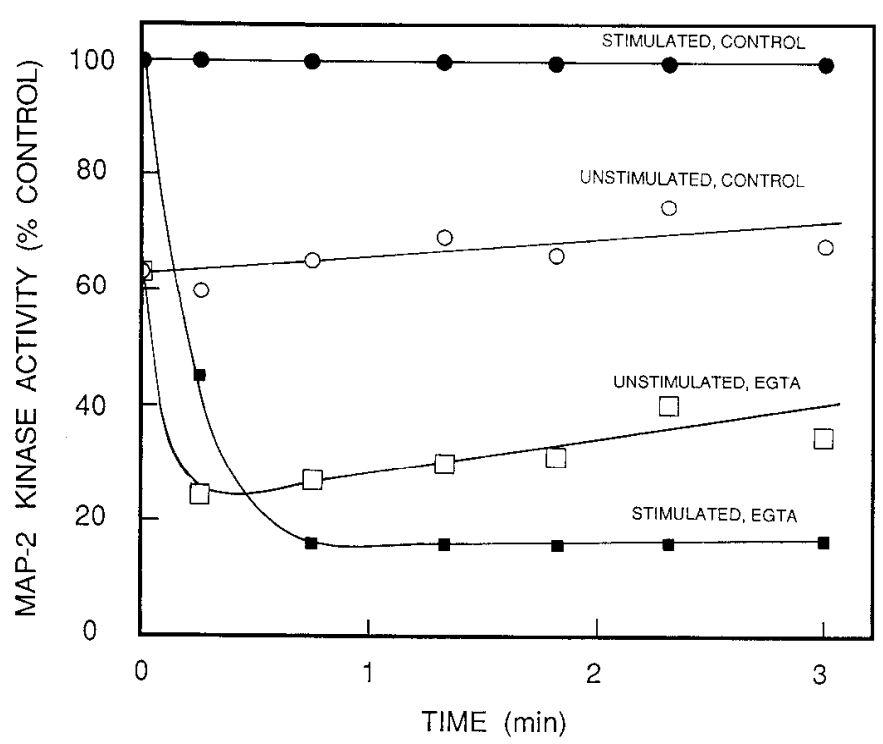

Figure 2. The effect of autonomous autophosphorylation on the activity of the kinase toward exogenous substrates. Kinase was converted to the autonomous state ( $63 \%$ autonomy) by prephosphorylating enzyme for $1 \mathrm{~min}$ with $500 \mu \mathrm{M}$ ATP in the presence of $\mathrm{Ca}^{2+} / \mathrm{calmodulin}$ as described in Figure 1. Autonomous autophosphorylation was initiated by chelating $\mathrm{Ca}^{2+}$ with EGTA ( $10 \mathrm{~mm}$ final concentration). Control samples received equal volumes of $\mathrm{H}_{2} \mathrm{O}$ instead of EGTA (-, O). The effect of this second phase of autophosphorylation on kinase activity was monitored by measuring MAP-2 phosphorylation in the presence $(\square$, STIMULATED) or absence $(O, \sqcap$; UNSTIMULATED) of added $\mathrm{Ca}^{2+} /$ calmodulin. MAP-2 phosphorylation was assayed for $15 \mathrm{sec}$ as previously described (Schulman, 1984) with stimulated control defined as $100 \%$. Both control and phosphorylated kinase samples lose approximately $10 \%$ activity per min of reaction at $30^{\circ} \mathrm{C}$. The data points represent an average of duplicate determinations which varied by less than $5 \%$. The data are representalive of several such experiments, which yielded essentially identical results.

reaction involving a prephosphorylation in the continuous presence of $\mathrm{Ca}^{2+}$ followed by incubation in either the presence or absence of $\mathrm{Ca}^{2+}$. In the prephosphorylation step, kinase became progressively more autophosphorylated upon exposure to $\mathrm{Ca}^{2+}$ calmodulin and $500 \mu \mathrm{M}$ ATP, until $32 \mathrm{~mol} \mathrm{P} / \mathrm{mol}$ holoenzyme was incorporated (Fig. 1, ). No autophosphorylation takes place if $\mathrm{Ca}^{2+}$ or calmodulin is omitted in the prephosphorylation step. Samples were withdrawn after $12 \sec (\triangle)$ or 1 min $(\square)$ of prephosphorylation, and $\mathrm{Ca}^{21}$ was chelated with EGTA to determine whether autophosphorylation would be sustained in the absence of $\mathrm{Ca}^{2+}$. It is apparent that prephosphorylation with $\mathrm{Ca}^{2+} /$ calmodulin allows the kinase to continue autophosphorylating without $\mathrm{Ca}^{2+}$. In fact, there is a "burst" of $\mathrm{Ca}^{2+}$-independent autophosphorylation that is more rapid and more extensive (up to $42 \mathrm{~mol} \mathrm{P} / \mathrm{mol}$ holoenzyme) than that seen in the continuous presence of $\mathrm{Ca}^{2+}$ (Fig. 1, $\triangle, \square$ ). The burst of autophosphorylation increases phosphate content by $30 \pm 8 \%$. If prephosphorylation is extended to 2 min so that maximal $\mathrm{Ca}^{3+}$ stimulated autophosphorylation is obtained, there is still an increment of phosphate incorporated when $\mathrm{Ca}^{2+}$ is removed (data not shown). In similar reactions, terminating the prephosphorylation at earlier time points, we found that the minimal phosphorylation yielding full autonomy for autophosphorylation is approximately $3 \mathrm{~mol} \mathrm{P} / \mathrm{mol}$ holoenzyme.

The autonomous phase of autophosphorylation appears to include novel sites of phosphorylation not seen during $\mathrm{Ca}^{2+}$ calmodulin-stimulated autophosphorylation. Differences in the

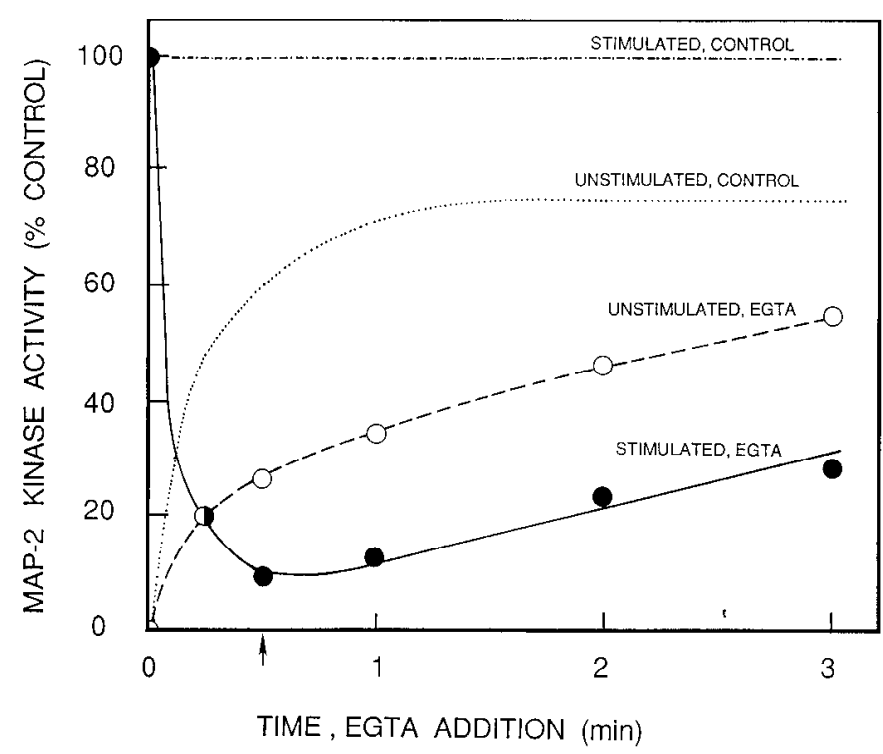

Figure 3. The effect of various degrees of $\mathrm{Ca}^{2+}$-stimulated autophosphorylation on subsequent autonomous autophosphorylation. The kinase was autophosphorylated in the presence of $\mathrm{Ca}^{2+} /$ calmodulin for various times up to $3 \mathrm{~min}$. At the times indicated an aliquot was sampled for autonomous MAP-2 kinase activity (UNSTIMULATED, CONTROL) and $\mathrm{Ca}^{2+}$-stimulated MAP-2 kinase activity (STIMULATED, CONTROL). Note that the abscissa for the control reactions represents time of prephosphorylation. EGTA was added to the remainder of the reaction mixture at each time point and the reaction continued for a second phase of autophosphorylation (autonomous) up to a total of 4 min for both phases. Results of MAP-2 phosphorylation in either the presence (- STIMULATED, EGTA) or absence (O; UNSTIMULAT$\mathrm{ED}, \mathrm{EGT} \Lambda$ ) of added $\mathrm{Ca}^{2+} /$ calmodulin are shown. The abscissa for these samples indicates the length of prephosphorylation, i.e., the time of addition of EGTA. The same data are obtained if a fixed period of autonomous autophosphorylation $(1 \mathrm{~min})$ follows the variable prephosphorylation. Both control and phosphorylated kinase samples lose approximately $10 \%$ activity per min of reaction at $30^{\circ} \mathrm{C}$. The data points represent an average of duplicate determinations which varied by less than $5 \%$. The data are representative of several such experiments, which yielded essentially identical results.

phosphorylation site specificity between these 2 phases of autophosphorylation are reflected by the mobility of the kinase on SDS gels (Fig. 1, inset). We have shown previously that mobility of multifunctional CaM kinase is sensitive to the site of autophosphorylation (Lou et al., 1986). After phosphorylation in the continuous presence of $\mathrm{Ca}^{2+} /$ calmodulin and $500 \mu \mathrm{M}$ ATP, the $\alpha$ subunit migrates primarily at $51 \mathrm{kDa}$ and the $\beta$ subunit migrates at $60 \mathrm{kDa}$. The burst of autophosphorylation shifts the $\alpha$ subunit to $52 \mathrm{kDa}$ and the $\beta$ subunit to $62 \mathrm{kDa}$. These mobility shifts are suggestive of the involvement of different phosphorylation sites. It is possible that they are sites normally blocked by bound $\mathrm{Ca}^{2+} /$ calmodulin and account for the incremental phosphate incorporated during autonomous autophosphorylation.

It was previously established that with increasing autophosphorylation in the presence of $\mathrm{Ca}^{2+} /$ calmodulin there is a progressive increase in autonomous phosphorylation of substrates (Saitoh and Schwartz, 1985; Lai et al., 1986; Lou et al., 1986; Miller and Kennedy, 1986; Schworer et al., 1986). The effect of the burst of autophosphorylation on subsequent phosphorylation of substrates was not examined in these early studies. Since the $\mathrm{Ca}^{2}$-dependent and $\mathrm{Ca}^{2+}$-independent phases of autophosphorylation appear to involve modification of different sites, we reasoned that they may have different consequences on kinase 


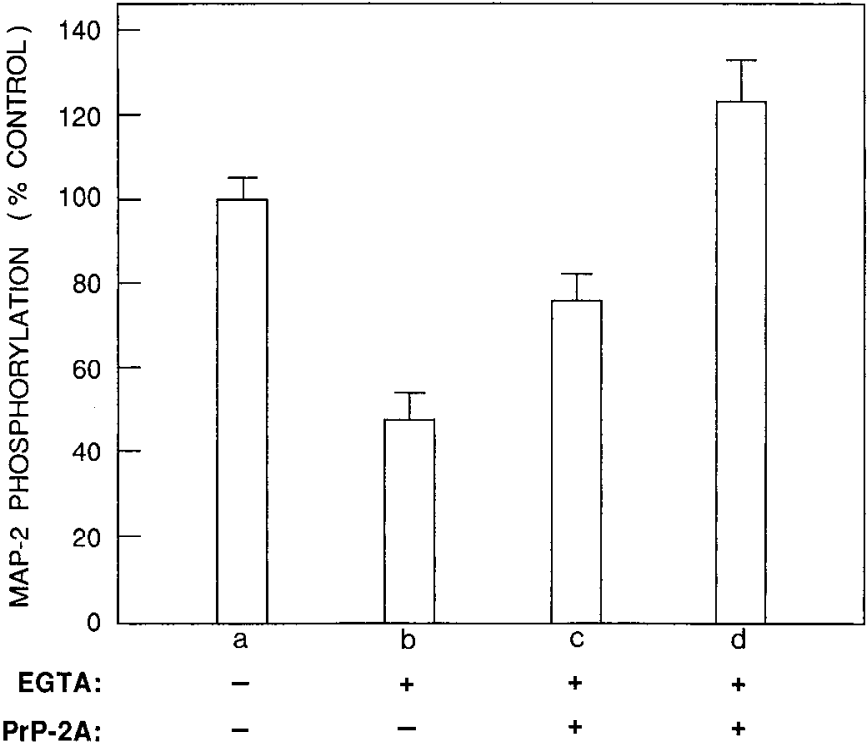

Figure 4. Reversal of kinase inhibition by phosphoprotein phosphatase-2A. Kinase (120 ng) was autophosphorylated with $500 \mu \mathrm{M}$ ATP at $30^{\circ} \mathrm{C}$ for $30 \mathrm{sec}$ in either the continuous presence of $\mathrm{CA}^{2+} / \mathrm{calmodulin}$ (reaction $a$ ) or with $\mathrm{Ca}^{2+} /$ calmodulin for $15 \mathrm{sec}$ followed by the inhibitory burst for an additional $15 \mathrm{sec}$ (reactions $b, c$, and $d$ ) as described in Figure 1. Autophosphorylation was terminated after the $30 \mathrm{sec}$ incubations by addition of EDTA ( $25 \mathrm{~mm}$ final concentration). Dephosphorylation was initiated immediately by addition of $250 \mathrm{ng}$ of purified phosphoprotein phosphatase-2A generously provided by $\mathrm{T}$. Ingebritsen (Shenolikar and Ingebritsen, 1984) (reactions $c$ and $d$ ), and the reaction terminated after $90 \sec$ (reaction $c$ ) or $3 \mathrm{~min}$ (reaction $d$ ). Equal volumes of buffer were added in place of phosphatase to reactions $a$ and $b$. The effects of autophosphorylation and of dephosphorylation were monitored by immediately assaying for MAP-2 phosphorylation in the presence of $\mathrm{Ca}^{2+} / \mathrm{calmodulin}$ as described in Figure 2. The concentrations of EGTA, phosphatase, and buffer were adjusted so that they were equal in the 4 samples during the MAP-2 phosphorylation assay. The presence of phosphatase did not affect determination of MAP-2 phosphorylation during the brief incubation. All values are normalized to that of the fully autophosphorylated kinase (reaction $a$ ), which did not undergo an inhibitory autophosphorylation or a reversal with phosphatase. Both control and phosphorylated kinase samples lose approximately $10 \%$ activity per min of reaction at $30^{\circ} \mathrm{C}$. Each value represents the average of 3 determinations \pm SEM.

function. We therefore assessed the effect of the $\mathrm{Ca}^{2+}$-independent phase of autophosphorylation on the ability of the kinase to phosphorylate exogenous substrates.

A sample of kinase was first made autonomous (63\% autonomy for MAP-2 phosphorylation) by prephosphorylation with $\mathrm{Ca}^{2+} /$ calmodulin. Autonomous autophosphorylation was then initiated by addition of EGIA. In the second step of the analysis, aliquots were taken at various times after chelation of $\mathrm{Ca}^{2+}$, and MAP-2 phosphorylation was assayed in either the presence (stimulated) or absence (unstimulated) of $\mathrm{Ca}^{2+}$ (Fig. 2). As a consequence of the chelation of $\mathrm{Ca}^{2+}$ there is a rapid and marked reduction in autonomous (unstimulated) MAP-2 kinase activity (Fig. 2, $\square$ ) and an even greater inhibition of $\mathrm{Ca}^{2+}$-stimulated MAP-2 kinase activity (Fig. 2, $\mathbf{\square}$ ). Autonomous MAP-2 phosphorylation is reduced from $63 \%$ to $23 \%$ within $15 \mathrm{sec}$. $\mathrm{Ca}^{2+} /$ calmodulin-stimulated phosphorylation of MAP-2 is reduced from $100 \%$ to $43 \%$ within the same period of time and to $16 \%$ of control by $45 \mathrm{sec}$. Thus, whereas the $\mathrm{Ca}^{2+}$-stimulated prephosphorylation produces an autonomous enzyme, removal of $\mathrm{Ca}^{2+}$ leads to a period of autonomous autophosphorylation (burst) that markedly reduces the ability of the kinase to phosphorylate its substrate.

We next determined whether inhibition by the burst of autophosphorylation is dependent on the amount of autonomy attained in the initial prephosphorylation. We carried out a series of experiments similar to that depicted in Figure 2 but starting with kinase at various degrees of autonomy, allowing the inhibitory burst of autophosphorylation to take place, and then assaying for residual MAP-2 kinase activity. In this experiment the time of $\mathrm{Ca}^{2+}$-stimulated prephosphorylation was varied from $15 \mathrm{sec}$ to $3 \mathrm{~min}$. Autonomous autophosphorylation was then initiated by chelation of $\mathrm{Ca}^{2+}$ and continued up to a total of $4 \mathrm{~min}$. MAP-2 kinase activity in either the presence (stimulated) or absence (unstimulated) of $\mathrm{Ca}^{2+}$ was then assayed and plotted vs time of prephosphorylation (Fig. 3). As a comparison we include a curve (dotted line) showing the amount of $\mathrm{Ca}^{2+}$-independent (unstimulated, control) MAP-2 kinase activity attained by the prephosphorylation prior to the inhibitory burst. As $\mathrm{Ca}^{2+}$-independent autophosphorylation proceeds, it reduces autonomous MAP-2 kinase activity (Fig. 3, O) as well as the stimulated MAP-2 kinase activity (Fig. 3, @). For example, if autonomous phosphorylation is initiated at $30 \mathrm{sec}$ and allowed to proceed $(3.5 \mathrm{~min}$ ), autonomous MAP-2 kinase activity is reduced from $60 \%$ to $25 \%$. Concurrently, the ability of $\mathrm{Ca}^{2+} /$ calmodulin to stimulate MAP-2 phosphorylation is lowered from $100 \%$ to $8 \%$. As the extent of prephosphorylation is increased the inhibitory effect of the burst is less severe, so that the amount of autonomous activity that persists is enhanced (e.g., compare "unstimulated, control" with "unstimulated, EGTA" in Fig. 3). Similar effects are seen with synapsin I as substrate (data not shown).

Inhibition is not a consequence of competition between autophosphorylation and exogenous substrate phosphorylation for the catalytic site because autonomous autophosphorylation is complete within $1 \mathrm{~min}$ (Fig. 1) and the inhibition of substrate phosphorylation persists for at least $3 \mathrm{~min}$ (Fig. 2). Addition of the ATP analogue, cordycepin-5'-triphosphate, after $15 \mathrm{sec}$ of prephosphorylation blocks the burst of autophosphorylation normally seen upon addition of EGTA and prevents the inhibition that normally accompanies it (data not shown). The inhibition is therefore dependent on phosphate incorporation. This was examined more directly by testing whether the inhibitory effect could be reversed by dephosphorylation. Kinase was prephosphorylated for $15 \mathrm{sec}$ with $\mathrm{Ca}^{2+} /$ calmodulin and then inhibited by approximately $50 \%$ by a $15 \mathrm{sec}$ incubation without $\mathrm{Ca}^{2+}$. The enzyme was then dephosphorylated with protein phosphates-2A for either $90 \mathrm{sec}$ or $3 \mathrm{~min}$. As shown in Figure 4 , the ability of $\mathrm{Ca}^{2+} /$ calmodulin to stimulate kinase activity is completely regained after dephosphorylation. Both dephosphorylation and deinhibition were dependent on the concentration of phosphates and the time of incubation.

We decided to examine the sites of autophosphorylation by tryptic phosphopeptide mapping as the first step in the identification of the sites responsible for the dramatically different effects of the 2 modes of autophosphorylation. We used several reaction conditions known to generate an autonomous kinase. We reasoned that the phosphopeptide(s) common to these different preparations of autonomous kinase would be the one(s) responsible for converting the kinase to $\mathrm{C}^{2+}$-independent form. Table 1 lists the 4 different prephosphorylation reactions chosen and the ability of each to convert the kinase to an autonomous form. The conditions found to best discriminate the sites of 
The Journal of Neuroscience, June 1989, 9(6) 2025

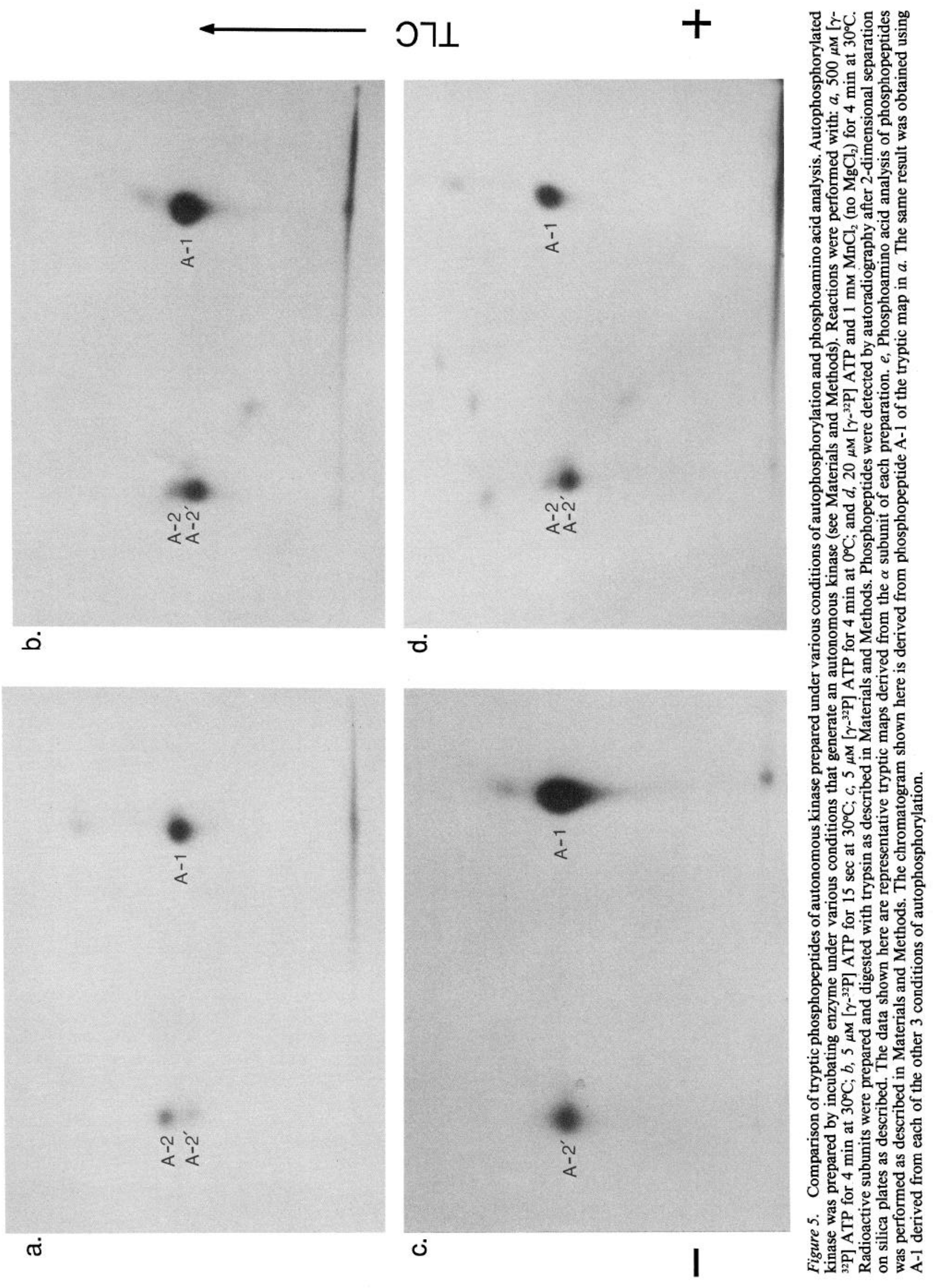




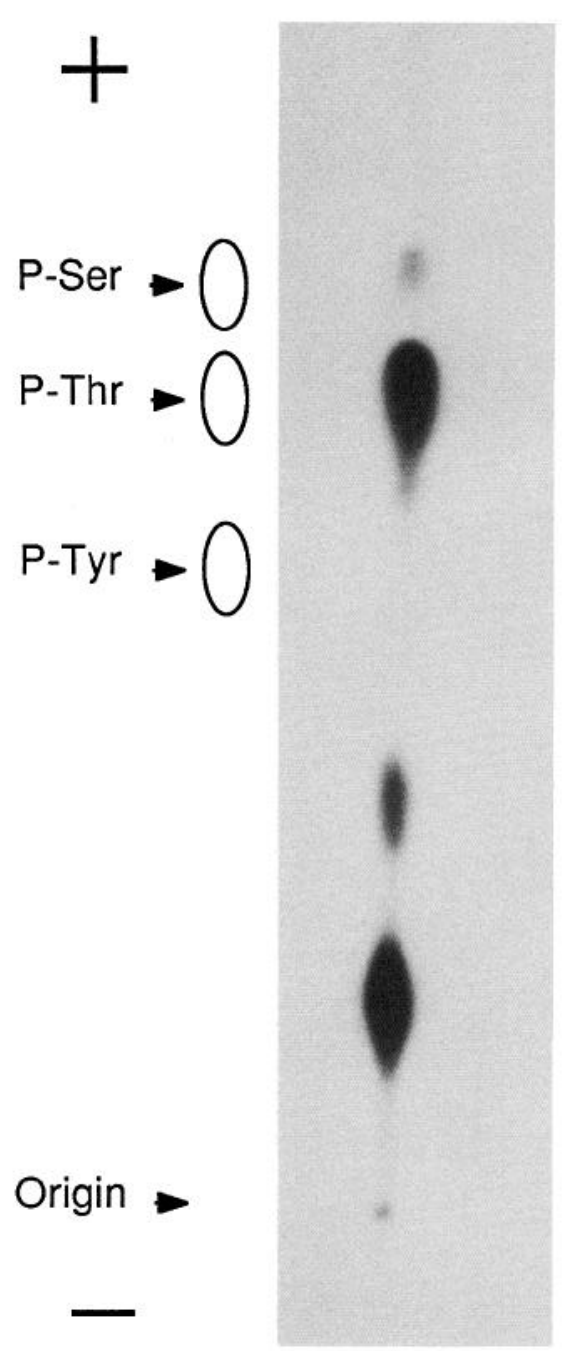

Figure 5. Continued.

phosphorylation are as follows: (1) phosphorylation with 500 $\mu \mathrm{M}$ ATP for $4 \mathrm{~min}$ at $30^{\circ} \mathrm{C}$ (our standard conditions); (2) $5 \mu \mathrm{M}$ ATP for $15 \mathrm{sec}$ at $30^{\circ} \mathrm{C}$. We have previously shown that extensive phosphorylation at $5 \mu \mathrm{M}$ ATP (e.g., $4 \mathrm{~min}$ ) leads to an inhibition or loss of kinase activity without any autonomy (Kuret and Schulman, 1985; Lou et al., 1986); however, partial autonomy (36\%) can be obtained even at such low levels of ATP if the time and extent of autophosphorylation are minimized; (3) $5 \mu \mathrm{M} \mathrm{ATP}$ at $0^{\circ} \mathrm{C}$ for $4 \mathrm{~min}$. The inhibitory effect of autophosphorylation with low ATP is not seen at $0^{\circ} \mathrm{C}$; (4) $20 \mu \mathrm{M}$ ATP and $1 \mathrm{mM} \mathrm{MnCl}_{2}$ for $4 \mathrm{~min}$ at $30^{\circ} \mathrm{C}$. Substitution of $1 \mathrm{mM}$ $\mathrm{Mn}^{2+}$ for $10 \mathrm{mM} \mathrm{Mg}^{2+}$ at $30^{\circ} \mathrm{C}$ markedly enhances the affinity of the kinase for ATP and leads to a fully autonomous kinase even after extensive autophosphorylation at low ATP (Table 1).

We examined the phosphorylation sites directly by performing 2-dimensional peptide fingerprinting of autophosphorylated $\alpha$ and $\beta$ subunits after trypsin digestion (Fig. 5). After maximal phosphate incorporation using standard conditions ( $500 \mu \mathrm{M}$ ATP at $30^{\circ} \mathrm{C}$ for $4 \mathrm{~min}$ ), 3 phosphopeptides can be seen. The same phosphopeptides - a prominent phosphopeptide (A-1) and 2, more basic, phosphopeptides with similar mobilities (A-2 and

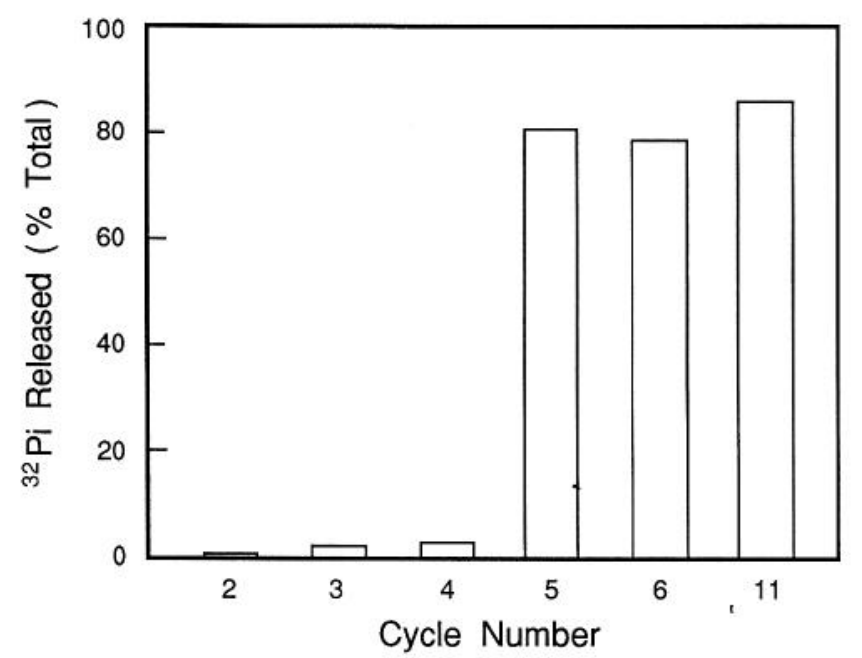

Figure 6. Identification of the "autonomy" site. The autonomy site was preferentially labeled by phosphorylation at $0^{\circ} \mathrm{C}$ as in Figure $5 c$. The ${ }^{32} \mathrm{P}$-labeled $\alpha$ subunit was isolated and cleaved with $\mathrm{CNBr}$ as described in Materials and Methods. The $\mathrm{CNBr}$ fragment was subjected to Edman degradation and the ${ }^{32} \mathrm{P}$ analyzed after the indicated sequencing cycles. Data represent the percentage of total radioactivity applied to the glass filter $(9000 \mathrm{cpm})$ that is in the form of ${ }^{32} \mathrm{Pi}$ at the end of each cycle.

A-2') - can be seen in all of the preparations. Comparison of the tryptic maps produced by the 4 conditions of autophosphorylation suggests that phosphorylation of a site(s) present in phosphopeptides A-1 and A-2' is most likely to be responsible for generating autonomy. Phosphopeptide A-2 is not phosphorylated at $0^{\circ} \mathrm{C}$ (Fig. $5 c$ ) and minimally phosphorylated under other conditions (Fig. 5, $a, b, d$ ). The ratio of phosphopeptide A-2' to A-1 is variable. Phosphopeptide A-1 is associated temporally with generation of an autonomous kinase. For example, at low ATP $\left(5 \mu \mathrm{M}\right.$ ATP and $10 \mathrm{mM} \mathrm{MgCl}_{2}$ at $\left.30^{\circ} \mathrm{C}\right)$ the kinase briefly becomes autonomous (by $15 \mathrm{sec}$ ) before losing activity (from 1 to $4 \mathrm{~min}$ ) (Lou et al., 1986). This loss of activity, which may include a component of thermolability (Lai et al., 1986), is accompanied by phosphorylation at many sites (data not shown). However, only peptides $\mathrm{A}-1$ and $\mathrm{A}-2^{\prime}$ are present at time of maximal autonomy (Fig. $5 b$ ). Substitution of $\mathrm{MnCl}_{2}$ for $\mathrm{MgCl}_{2}$, even at low ATP (Fig. $5 d$ ), reduces or eliminates phosphorylation at these additional sites and maintains the kinase in an autonomous form. Analysis of the $\beta$ subunit shows that phosphopeptides A-1 and A-2' are also prominent phosphopeptides, although other phosphopeptides are found (data not shown). Analysis of the tryptic phosphopeptides by HPLC also shows that phosphopeptide A-1 is the predominant phosphopeptide common to each of the 4 conditions used to generate autonomy (data not shown). Phosphoamino acid analysis of phosphopeptides A-1 (Fig. 5e) shows that it contains primarily phosphothreonine. Phosphopeptide A-2' contains phosphothreonine, whereas A-2 contains phosphoserine (data not shown).

Based on the site specificity of the multifunctional CaM kinase (Kemp et al., 1987) we surmised that the critical autophosphorylation might be near the calmodulin-binding domain at threonine ${ }^{253}$ or threonine ${ }^{286}$ (Lin et al., 1987). Fortuitously, chemical cleavage at methionines with $\mathrm{CNBr}$ is expected to generate only 2 low-molecular-weight, cysteine-containing peptides, each containing one of the putative "autonomy" sites. One $\mathrm{CNBr}$ fragment (amino acids 252-281) contains threonine ${ }^{253}$ 
as the second residue, whereas the second fragment (amino acids 282-307) contains threonine ${ }^{286}$ as the fifth residue. We therefore isolated the CNBr fragment from $\alpha$ subunit phosphorylated under conditions as in Figure $5 c\left(0^{\circ} \mathrm{C}, 5 \mu \mathrm{M}\right.$ ATP), a condition in which $85 \%$ of the phosphate is found in phosphopeptides A-1 and $A-2^{\prime}$. A single, low-molecular-weight, cysteine-containing phosphopeptide was isolated with $60 \%$ yield of ${ }^{32} \mathrm{P}$. Analysis of ${ }^{32} \mathrm{P}$-labeled material after each cycle of sequencing (Fig. 6) reveals that $80 \%$ of the label was released as ${ }^{32} \mathrm{Pi}$ at the fifth cycle. Thus, phosphorylation at threonine ${ }^{286}$ is responsible for converting the multifunctional $\mathrm{CaM}$ kinase into $\mathrm{C} \mathrm{Ca}^{2+}$-independent form. Since the same sample that is labeled predominantly at threonine ${ }^{286}$ yields 2 phosphothreonine-containing peptides (A-1 and $\left.\mathrm{A}-2^{\prime}\right)$, it is possible that these both contain threonine ${ }^{286}$. Phosphopeptide A-1 may be variably converted to A-2' by the cyclization of its N-terminal glutamine.

The finding that the burst autophosphorylation differs from the initial $\mathrm{Ca}^{2+}$ - stimulated autophosphorylation in its effect on substrate phosphorylation (Fig. 2) as well as in its effect on mobility of the kinase on SDS gels (Fig. 1, inset) suggests the involvement of different sites. This was examined directly by tryptic phosphopeptide mapping. Autophosphorylation was performed with a 2 -step reaction consisting of a prephosphorylation with $\mathrm{Ca}^{2+}$ and unlabeled ATP followed either by continued $\mathrm{Ca}^{2+}$-dependent autophosphorylation (Fig. $7 a$ ) or by a burst of $\mathrm{Ca}^{2+}$-independent autophosphorylation (Fig. $7 b$ ) with radioactively labeled ATP. Comparison of the phosphopeptide patterns indicates that 3 novel phosphopeptides, I-1, I- ${ }^{\prime}$ and I-2, are generated during the burst of autophosphorylation. Phosphopeptide $1-1^{\prime}$ may represent an incompletely digested form of phosphopeptide I-1, since it decreases with increasing trypsin (data not shown). The novel phosphopeptides are not seen even after extensive phosphorylation in the continuous presence of $\mathrm{Ca}^{2+} /$ calmodulin (Fig. 7a). Presumably, they account for the increment in phosphate incorporation seen during the burst (Fig. 1). Although phosphopeptides A-1 and A-2' continue to be phosphorylated during $\mathrm{Ca}^{2+}$-independent autophosphorylation, their functional effect is dominated by the inhibitory effects of phosphorylation at phosphopeptides I-1, I-1' and I-2. Appearance of these phosphopeptides correlates temporally with the burst (within the first $15 \mathrm{sec}$ of autonomous autophosphorylation) and with the inhibition of substrate phosphorylation. Although phosphopeptides I-1 and I-1' appear earliest (data not shown), phosphopeptide I-2 also is significantly phosphorylated during the initial burst, when most of the inhibition occurs (Fig. 2). Phosphoamino acid analysis shows that I-2 contains phosphoserine and I- 1 contains primarily phosphothreonine (Fig. $7 \mathrm{c}$ ). Phosphopeptide I- $1^{\prime}$ also contains primarily phosphothreonine (data not shown). Thus, phosphorylation at either the serine residue, the threonine residue, or both, is responsible for the inhibitory effect.

\section{Discussion}

Autophosphorylation regulates the multifunctional CaM kinase with a complexity that we are beginning to understand based on structural/functional data. Upon activation by $\mathrm{Ca}^{2+} /$ calmodulin, the multifunctional CaM kinase becomes maximally active and simultaneously begins to phosphorylate its substrates as well as itself. This autophosphorylation releases it from the stringent requirement for $\mathrm{Ca}^{2+} /$ calmodulin and thereby converts it to an autonomous or $\mathrm{Ca}^{2+} /$ calmodulin-independent kinase. In fact, it appears that as few as $2-3 \mathrm{~mol}$ phosphate per holo-
Table 1. Effect of various autophosphorylation conditions on generation of autonomous MAP-2 kinase activity

\begin{tabular}{lc} 
Autophosphorylation reaction & $\begin{array}{l}\text { Autonomous activity } \\
\text { (\% unstimulated/ } \\
\text { stimulated })\end{array}$ \\
\hline $500 \mu \mathrm{M} \mathrm{ATP}$ & $79.9 \pm 4.8$ \\
$30^{\circ} \mathrm{C}, 4 \mathrm{~min}$ & $35.6 \pm 3.9$ \\
$5 \mu \mathrm{M}$ ATP & $79.5 \pm 0.0$ \\
$30^{\circ} \mathrm{C}, 15 \mathrm{sec}$ & \\
$5 \mu \mathrm{M}$ ATP & $126.0 \pm 14.8$ \\
$0^{\circ} \mathrm{C}, 4 \mathrm{~min}$ & \\
$20 \mu \mathrm{M}$ ATP & \\
$30^{\circ} \mathrm{C}, 1 \mathrm{mM} \mathrm{MnCl}_{2}, 4 \mathrm{~min}$ &
\end{tabular}

Purified kinase was autophosphorylated in a preincubation using nonradioactive ATP with several variations to standard conditions as described in Materials and Methods. MAP-2 phosphorylation was immediately assayed in a second incubation (10 sec reaction) under the stimulated and unstimulated conditions as described. Each value represents the average of 3 determinations \pm SEM.

enzyme out of a maximal possible incorporation of approximately $30 \mathrm{~mol}$ phosphate is sufficient for this process (Miller and Kennedy, 1986). Under optimal conditions described here, we found that after reaching "threshold" for autonomy, autophosphorylation proceeds at a much faster rate if $\mathrm{Ca}^{2+}$ is removed than if it is continuously present. In addition, there is an increment in total phosphate incorporation. The dramatic increase in autophosphorylation rate (Figs. 1,6) suggests that although $\mathrm{Ca}^{2+} /$ calmodulin is essential for kinase activation, it may sterically interfere with the autophosphorylation. Interestingly, neither the burst nor the incremental, autophosphorylation occurs with an autonomous kinase at $0^{\circ} \mathrm{C}$ (unpublished observations). At this temperature the complex subunit interactions in this enzyme appear to be affected in a qualitative as well as a quantitative manner. Not only is the rate of reaction reduced, but the maximal degree of autophosphorylation is reduced by nearly 90\% (Lai et al., 1986) and the autonomous mode of autophosphorylation lacks the inhibitory phosphorylation (unpublished observations). Miller and Kennedy (1986) and Hashimoto et al. (1987) reported an increased rate of autophosphorylation of only the $\beta$ subunit or both subunits, respectively, but neither found a significant increment in maximal phosphate incorporation resulting from autonomous autophosphorylation. Hashimoto et al., (1987) did find an inhibitory effect of the autophosphorylation, consistent with our results. The ability to block both the burst of autophosphorylation and consequent inhibition with cordycepin-5'-triphosphate and the complete reversal of the inhibitory effect by phosphatase suggest that inhibition is a direct consequence of phosphate incorporation.

We show that autonomous autophosphorylation is a mode of autophosphorylation distinct from $\mathrm{Ca}^{2+}$-dependent autophosphorylation. This mode of autophosphorylation substantially reduces both $\mathrm{Ca}^{2+}$ /calmodulin-dependent and -independent phosphorylation of substrate proteins (Fig. 2). This finding contrasts with a recent study that found no effect of autonomous autophosphorylation on $\mathrm{Ca}^{2+}$-independent $\mathrm{CaM}$ kinase activity (Hashimoto et al., 1987). It is possible that this potentially important effect was missed, because that study dealt only with kinase that was extensively prephosphorylated. As shown in Figure 3 , the degree of inhibition, especially of the $\mathrm{Ca}^{2+}$-independent activity, is attenuated by extensive $\mathrm{Ca}^{2+}$-dependent pre- 


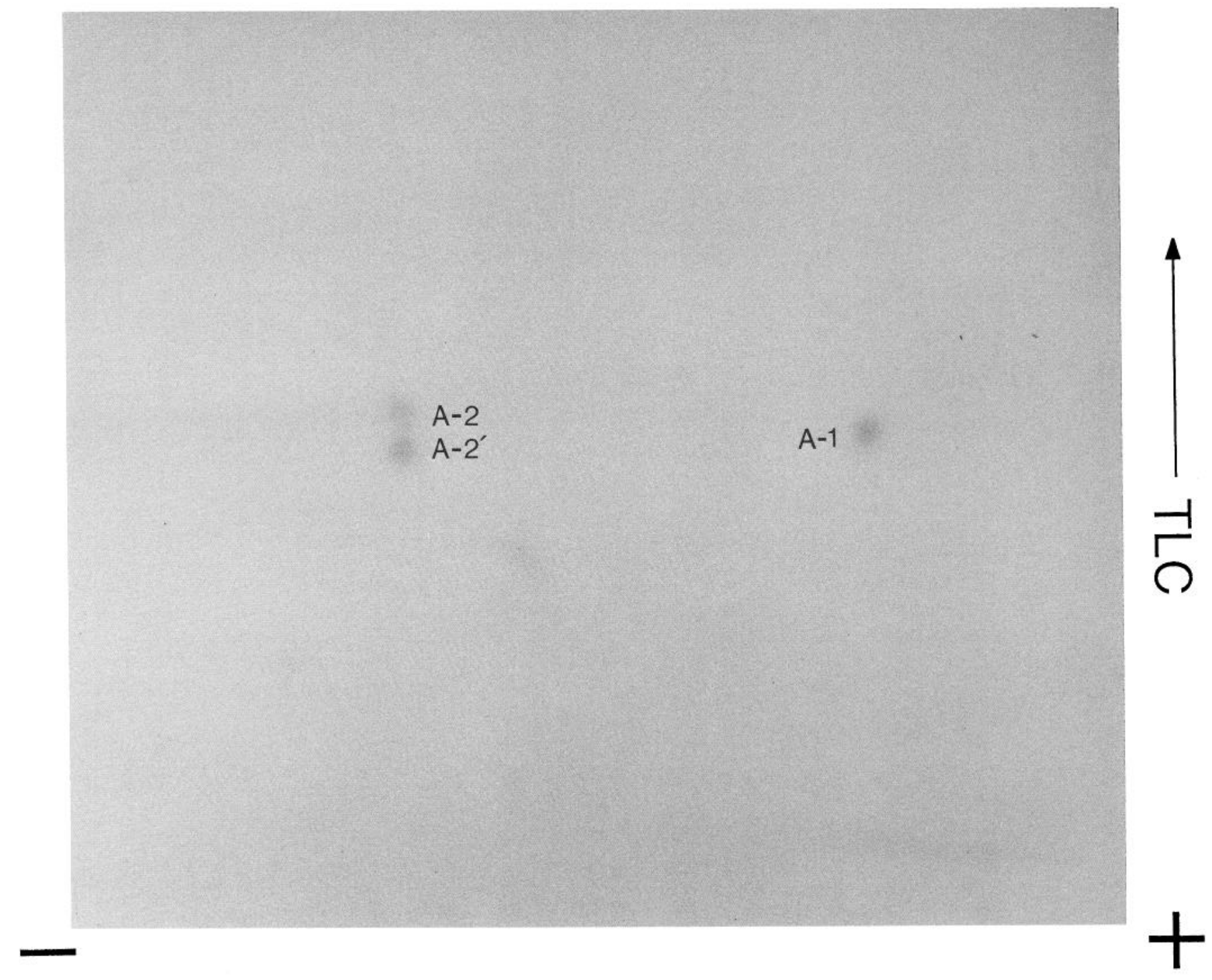

Figure 7. Tryptic peptide mapping of $\mathrm{Ca}^{2+} /$ calmodulin-dependent and -independent autophosphorylation sites. Kinase was first made autonomous by incubation in the presence of $\mathrm{Ca}^{2+}$ calmodulin for $15 \mathrm{sec}$ with $500 \mu \mathrm{M}$ ATP (unlabeled). $a, \mathrm{Ca}^{2+}$-dependent autophosphorylation sites were labeled by incubating half of the reaction for an additional $15 \mathrm{sec}$ with $500 \mu \mathrm{M}\left[\gamma^{-32} \mathrm{P}\right] \mathrm{ATP} . b, \mathrm{Ca}^{2+}$-independent autophosphorylation sites were labeled by incubating the other half of the reaction for an additional $15 \mathrm{sec}$ with $500 \mu \mathrm{M}\left[\gamma^{-32} \mathrm{P}\right]$ ATP in the absence of CA ${ }^{2+}$, as described in Figure

phosphorylation. Furthermore, the full effect of the inhibitory "burst" may not occur at the concentration of ATP that was used (100 $\mu \mathrm{M}$ ATP). The existence of an inhibitory phase that follows autonomous autophosphorylation suggests that the autonomous activity cannot be maintained at the level attained during the $\mathrm{Ca}^{2+}$-dependent autophosphorylation.

It is tempting to speculate that a major role of autophosphorylation in vivo is to enhance and prolong the effectiveness of intermittent and transient elevation of $\mathrm{Ca}^{2+}$. This proposed role for autophosphorylation is functionally analogous to that of the cAMP-deperdent protein kinase, although it is mechanistically quite different (Rangel-Aldao and Rosen, 1976). Activation of the multifunctional $\mathrm{CaM}$ kinase produced by either a strong stimulus, closely spaced stimuli, or the opening of some distinct type of $\mathrm{Ca}^{2+}$ channel may produce the "critical" stimulus that raises autophosphorylation to threshold (approximately 3 mol P per holoenzyme). As $\mathrm{Ca}^{2+}$ levels decline, the kinase would temporarily be able to phosphorylate substrates in $\mathrm{a} \mathrm{Ca}^{2+} / \mathrm{cal}-$ modulin-independent manner. However, autophosphorylation would continue at an even faster rate, and this distinct mode of autophosphorylation would reduce substrate phosphorylation. The relationship between periods of high and low $\mathrm{Ca}^{2+}$ (frequency and amplitude) may have different effects on autonomy and inhibition of substrate phosphorylation. Furthermore, phosphoprotein phosphatases may have a critical role in regulating the degree of activation required for "threshold" to be attained as well as in separately regulating the "autonomy" (phosphothreonine-containing) and "inhibitory" (phosphoserine- and phosphothreonine-containing) sites on the kinase.

What does the dual modulation of kinase by autophosphorylation suggest about the "memory" model? According to the model, the kinase must maintain its ability to phosphorylate substrates in the absence of the initial signal in order to function in long-term information storage (Crick, 1984; Lisman, 1985; Miller and Kennedy, 1986; Lisman and Goldring, 1988). We show, however, that while the autophosphorylated state can be 


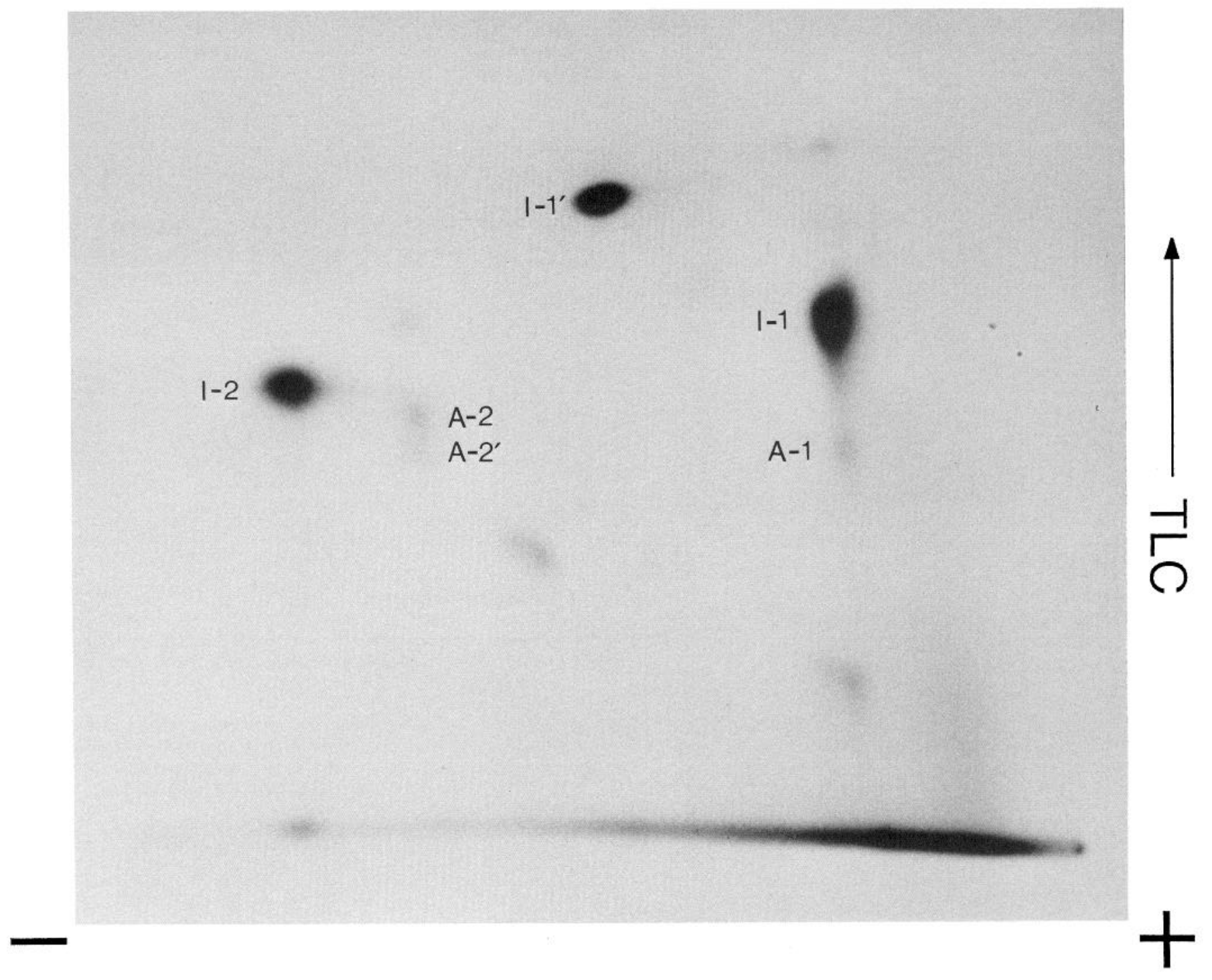

1. Tryptic phosphopeptides derived from kinase subunits were separated in 2 dimensions and analyzed by autoradiography as described in Materials and Methods. $c$, Phosphoamino acid analysis was performed for phosphopeptides I-1 and I-2 derived from the $\alpha$ subunit of kinase autophosphorylated as described above.

maintained (or even enhanced), kinase activity towards substrates is not. Residual kinase activity is particularly attenuated if the initial exposure to $\mathrm{Ca}^{2+}$ is brief (Fig. 3). Lowering the residual autonomy for substrate phosphorylation can drastically reduce the constitutive activity of the kinase that was attained during the initial stimulus and makes it easier for phosphatases to reverse its effects on substrate proteins. We suggest that there are 2 possible biochemical readouts of such a phosphorylation system. The first is the enzymatic role of the kinase in substrate phosphorylation. This function may be important while intracellular $\mathrm{Ca}^{2+}$ is elevated and for a short time afterwards, before the inhibitory burst of autophosphorylation is complete. It is intriguing, however, that a brief stimulus followed by a period with low $\mathrm{Ca}^{2+}$ can generate a highly autophosphorylated kinase molecule (up to $42 \mathrm{~mol} P$ per holoenzyme) with the ability to maintain its state of autophosphorylation in the absence of $\mathrm{Ca}^{2+}$ but with minimal ability to catalyze substrate phosphorylation. Such a protein might have a nonenzymatic role in short-term information storage and may be the second and critical biochemical readout of the system. The history of synaptic activity could be coded by the amount of the phosphorylated form of this protein at a synapse. The high concentration of the multifunctional CaM kinase in brain $(0.25 \%$ of total brain protein and $2 \%$ of hippocampal protein; Erondu and Kennedy, 1985) and its translocation upon autophosphorylation in Aplysia (Saitoh and Schwartz, 1985) are consistent with this possibility.

A single common site appears to be phosphorylated under all conditions that produce an autonomous kinase. We took advantage of the fact that at low ATP $(<25 \mu \mathrm{M})$ autonomy is generated when the reaction is carried out at $0^{\circ} \mathrm{C}$ or, when it is carried out at $30^{\circ} \mathrm{C}$, only if autophosphorylation either is not extensive (e.g., $15 \mathrm{sec}$ ) or is extensive but carried out with $\mathrm{Mn}^{2+}$ rather than $\mathrm{Mg}^{2+}$ as the divalent metal ion. Using these as well as the standard condition of $500 \mu \mathrm{M}$ ATP and $30^{\circ} \mathrm{C}$ allowed us to determine that phosphopeptides A-1 and A-2' contain the site whose phosphorylation correlates with the autonomous state. 


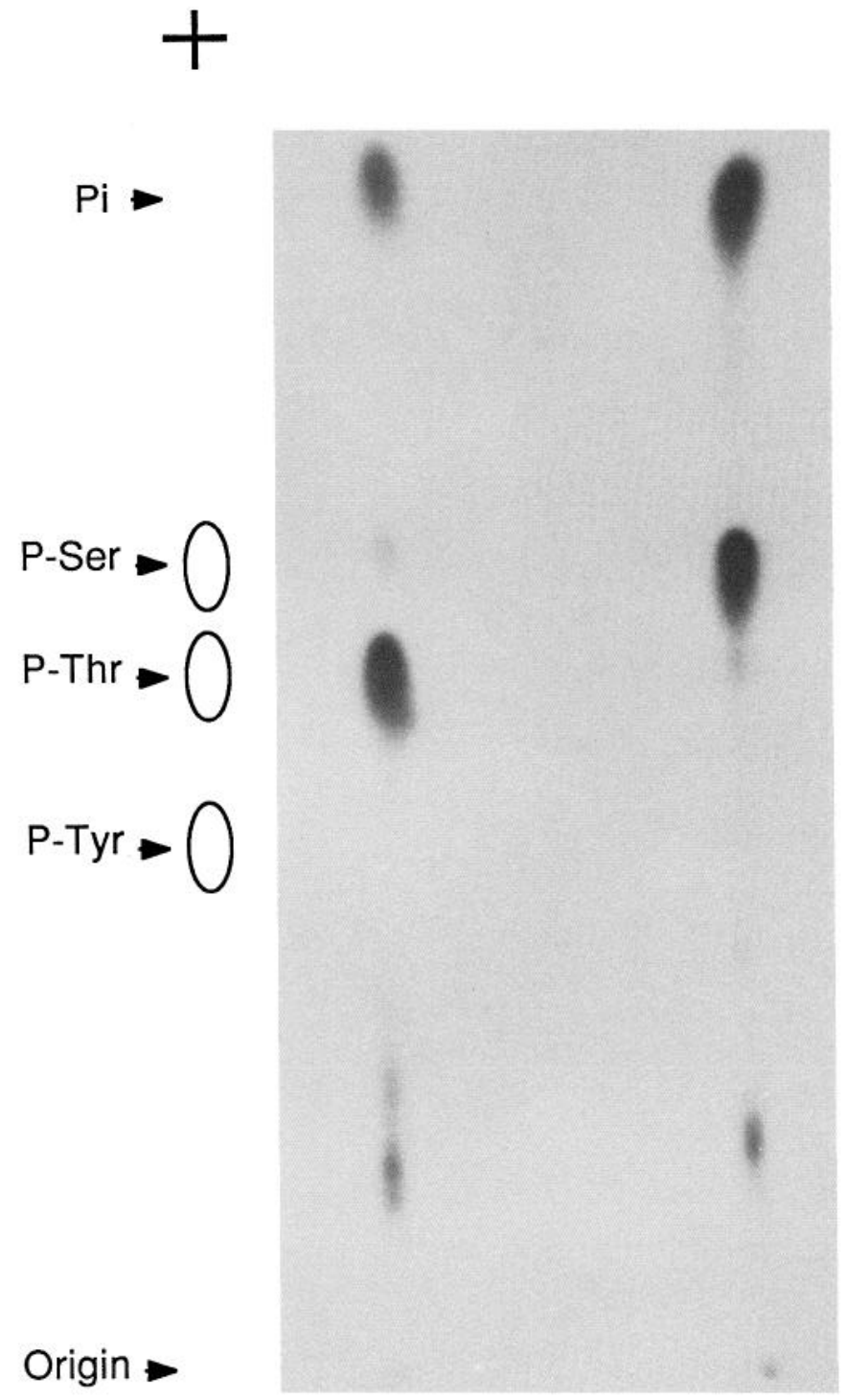

Figure 7. Continued.

None of the other phosphopeptides, including the serine-containing phosphopeptide A-2, are found in significant amounts in each preparation of kinase. The critical phosphorylation site is threonine ${ }^{286}$. Since we and others (Lai et al., 1986; Lou et al., 1986; Miller and Kennedy, 1986; Schworer et al., 1986) have previously demonstrated that phosphate incorporation rather than some indirect effect of $\mathrm{Ca}^{2+} /$ calmodulin produces the autonomous kinase, phosphorylation of threonine ${ }^{286}$ must be responsible for this dramatic functional effect. This location is consistent with the known site specificity of the kinase for its substrates (Kemp et al., 1987) and with indications that the sites of calmodulin binding and autophosphorylation overlap (Shields et al., 1984). The core of the sequence, Arg-Gln-Glu-Thr ${ }^{286}$ (Lin et al., 1987), is also found in the $\beta$ subunit (Bennett and Kennedy, 1987) and suggests that the "autonomy" site of the 2

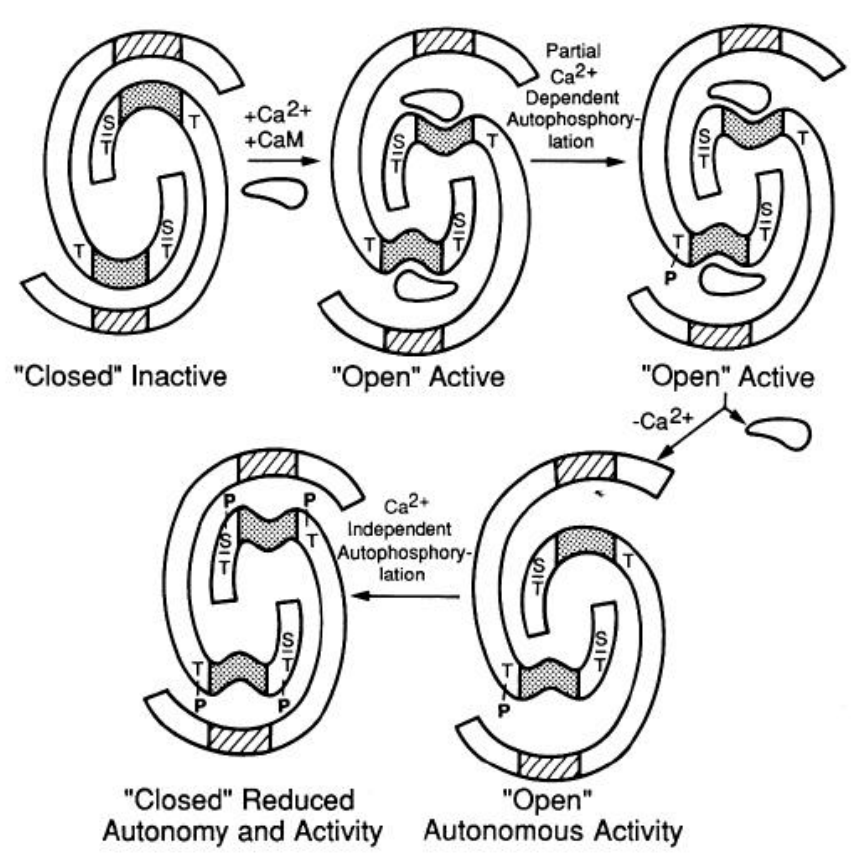

Figure 8. Three-domain model of multifunctional CaM kinase depicting regulation of the kinase by $\mathrm{Ca}^{2+} /$ calmodulin and by autophosphorylation. Activation by $\mathrm{Ca}^{2+} /$ calmodulin is depicted as the displacement of the "pseudosubstrate" region from the active site. Autophosphorylation at a threonine (T-P) prevents this region from inhibiting once $\mathrm{Ca}^{2+} /$ calmodulin dissociates. In addition, it may act cooperatively to activate the unphosphorylated neighboring subunit. Dissociation of $\mathrm{Ca}^{2+} /$ calmodulin brings a serine and threonine into position for phosphorylation $(S / P)$ that is inhibitory to further autonomous and $\mathrm{Ca}^{2+} /$ calmodulin-dependent phosphorylation of substrates.

subunits is identical. We have recently constructed a site-directed mutant in which $\mathrm{Thr}^{286}$ has been replaced by a nonphosphorylated residue. We found the resulting kinase to be fully activated by $\mathrm{Ca}^{2+} /$ calmodulin but incapable of autonomous phosphorylation of substrates, consistent with the identification of $\mathrm{Thr}^{286}$ as the autonomy site (unpublished observations). While this manuscript was in review, several studies reported that $\mathrm{Thr}^{286}$ is the phosphorylation site on the $\alpha$ subunit that correlates with generation of an autonomous kinase (Miller et al., 1988; Schworer et al., 1988; Thiel et al., 1988).

The dual modulation of kinase activity by autophosphorylation can be explained by the involvement of different sites. During the burst of autophosphorylation, the autonomy site continues to be phosphorylated, but 3 additional sites, represented in phosphopeptides I-1, I- ${ }^{\prime}$ and I-2, become phosphorylated. This phosphorylation accounts for the increment in phosphate incorporation. Either one or both of these is responsible for reducing the autonomous activity and $\mathrm{Ca}^{2+}$-stimulated activity of the kinase.

We can begin to appreciate the regulation of the multifunctional CaM kinase based on recent sequence information obtained by molecular cloning of the $\alpha$ (Lin et al., 1987) and $\beta$ (Bennett and Kennedy, 1987) subunits and analysis of its calmodulin-binding and inhibitory domains (Payne et al., 1988). The 2 subunits contain 3 homologous domains. The $\mathrm{N}$-terminal half of the protein constitutes the catalytic domain. This is followed by a regulatory domain that includes a basic amino acidrich region which is analogous to the calmodulin-binding domain of MLCK (Blumenthal et al., 1985; Edelman et al., 1985; 
Lukas et al., 1986). Finally, the carboxy-terminal third of the molecule is highly hydrophilic, lacks homology to other proteins, and may be involved in assembly of subunits within the holoenzyme or association of the kinase with intracellular organelles.

A model depicting how the multifunctional CaM kinase is regulated based on the sequence information, on its physical characteristics, and by analogy to MLCK (Kemp et al., 1987; Kennelly et al., 1987) is shown in Figure 8. The model is drawn for a pair of $\alpha$ subunits, but a similar mechanism can be envisioned for the $\beta$ subunit as well. We chose to depict the 2 subunits in an antiparallel fashion based on analogy with cGMPdependent protein kinase (Gill, 1977). The calmodulin-binding domain is near an inhibitory domain that sterically blocks access of substrate to the catalytic site of the enzyme and thereby maintains it in an inhibited state (Hanley et al., 1987; Lin et al., 1987; Payne et al., 1988). In the absence of $\mathrm{Ca}^{2+}$ the regulatory region of one subunit is shown to inhibit the active site of its neighboring subunit. The $\mathrm{Ca}^{2+} /$ calmodulin complex activates the kinase by displacing this inhibitory domain away from the active site. Such a model predicts that proteolytic removal of this region would generate an active kinase. Indeed, limited proteolysis of the multifunctional CaM kinase produces a monomeric and catalytically "autonomous" fragment (LeVine and Sahyoun, 1987).

We accommodate the findings on autonomy reported above by depicting that autophosphorylation of threonine ${ }^{286}$, near the inhibitory and calmodulin-binding domains, maintains the "open" conformation normally produced by $\mathrm{Ca}^{2+} /$ calmodulin binding. Autophosphorylation is an intramolecular reaction but may involve either inter- or intra-subunit phosphorylation (Kuret and Schulman, 1985). The model shows an inter-subunit autophosphorylation. The model also suggests that within a dimeric unit, autophosphorylation of one subunit can maintain the catalytic domain of the other subunit in an open or $\mathrm{Ca}^{2+}$ independent conformation as well. Such interactions may explain why autophosphorylation of only a few of the subunits can convert the entire holoenzyme into an autonomous form.

The inhibitory phase of multifunctional CaM kinase autophosphorylation resembles the regulation of smooth muscle MLCK. Both kinases can be inhibited by phosphorylation at a site protected by the binding of calmodulin. The cAMP-dependent protein kinase inhibits MLCK by phosphorylating it at a serine residue near the calmodulin-binding domain (Conti and Adelstein, 1981; Lukas et al., 1986). There are only 2 serinecontaining consensus sequences for autophosphorylation outside of the catalytic domain of the multifunctional CaM kinase, Arg-Asn-Phe-Ser ${ }^{314}$ and Lys-Glu-Ser-Ser ${ }^{331}$. Interestingly, Ser ${ }^{314}$ is at the position on the carboxy-terminal end of the calmodulinbinding domain precisely homologous to that of the inhibitory serine in MLCK (Lukas et al., 1986; Lin et al., 1987). The same sequence is also found in the homologous position in the $\beta$ subunit (Bennett and Kennedy, 1987). This may be one of the inhibitory sites that account for the incremental burst of autophosphorylation seen upon dissociation of calmodulin from the multifunctional CaM kinase.

\section{References}

Beemon, K., and T. Hunter (1978) Characterization of Rous sarcoma virus src gene products synthesized in vitro. J. Virol. 28: 551-566.

Bennett, M. K., and M. B. Kennedy (1987) Deduced primary structure of the $\beta$ subunit of brain type II $\mathrm{Ca}^{2+} /$ calmodulin-dependent protein kinase determined by molecular cloning. Proc. Natl. Acad. Sci. USA 84: $1794-1798$.

Berridge, M. J., and R. F. Irvine (1984) Inositol trisphosphate, a novel second messenger in cellular signal transduction. Nature $312: 315-$ 321.

Blumenthal, D. K., K. Takio, A. M. Edelman, H. Charbonneau, K. Titani, K. A. Walsh, and E. G. Krebs (1985) Identification of the calmodulin-binding domain of skeletal muscle myosin light chain kinase. Proc. Natl. Acad. Sci. USA 82: 3187-3191.

Bulleit, R. F., M. K. Bennett, S. S. Molloy, J. B. Hurley, and M. B. Kennedy (1988) Conserved and variable regions in the subunits of brain type $\mathrm{II} \mathrm{Ca}^{2+} /$ calmodulin-dependent protein kinase. Neuron 1 : 63-72.

Connelly, P. A., R. B. Sisk, H. Schulman, and J. C. Garrison (1987) Evidence for the activation of the multifunctional $\mathrm{Ca}^{2+} / \mathrm{calmodulin-}$ dependent protein kinase in response to hormones that increase intracellular $\mathrm{Ca}^{2+}$. J Biol. Chem. 262: 10154-10163.

Conti, M. A., and R. S. Adelstein (1981) The relationship between calmodulin binding and phosphorylation of smooth muscle myosin kinase by the catalytic subunit of $3^{\prime}: 5^{\prime}$ cAMP-dependent protein kinase. J. Biol. Chem. 256: 3178-3181

Crick, F. (1984) Memory and molecular turnover. Nature 312: 101.

Edelman, A. M., K. Takio, D. K. Blumenthal, R. S. Hansen, K. A. Walsh, K Titani, and E. G. Krebs (1985) Characterization of the calmodulin-binding and catalytic domains in skeletal muscle myosin light chain kinase. J. Biol. Chem. 260: 11275-11285.

Edelman, A. M., D. K. Blumenthal, and E. G. Krebs (1987) Protein serine/threonine kinases. Annu. Rev. Biochem. 56: 567-613.

Erondu, N. E., and M. B. Kennedy (1985) Regional distribution of type II $\mathrm{Ca}^{2+} /$ calmodulin-dependent protein kinase in rat brain. $\mathrm{J}$. Neurosci. 5: 3270-3277.

Fiol, C. J., A. M. Mahrenholz, Y. Wang, R. W. Roeske, and P. J. Roach (1987) Formation of protein kinase recognition sites by covalent modification of the substrate. Molecular mechanism for the synergistic action of casein kinase II and glycogen synthase kinase 3. J. Biol. Chem. 262: 14042-14048.

Gill, G. N. (1977) A hypothesis concerning the structure of cAMPand CGMP-dependent protein kinase. J. Cyclic Nucleotide Res. 3: 153-162.

Griffith, L. C., and H. Schulman (1988) The multifunctional $\mathrm{Ca}^{2+}$ calmodulin-dependent protein kinase mediates $\mathrm{Ca}^{2+}$ action in $\mathrm{PC} 12$ cells. J. Biol. Chem. 263: 9542-9549.

Hanley, R. M., A. R. Means, T. Ono, B. E. Kemp, K. E. Burgin, N. Waxham, and P. T. Kelly (1987) Functional analysis of a complementary DNA for the 50-kilodalton subunit of calmodulin kinase II. Science 237: 293-297.

Hashimoto, Y., C. M. Schworer, R. J. Cobran, and T. R. Soderling (1987) Autophosphorylation of $\mathrm{Ca}^{2+} /$ calmodulin-dependent protein kinase II. Effects on total and $\mathrm{Ca}^{2+}$-independent activities and kinetic parameters. J. Biol. Chem. 262: 8051-8055.

Herzog, W., and K. Weber (1978) Fractionation of brain microtubuleassociated proteins. Isolation of two different proteins which stimulate tubulin polymerization in vitro. Eur. J. Biochem. 92: 1-8.

Kemp, B. E., R. B. Pearson, V. Guerriero, Jr., I. C. Bagchi, and A. R. Means (1987) The calmodulin binding domain of chicken smooth muscle myosin light chain kinase contains a pseudosubstrate sequence. J. Biol. Chem. 262: 2542-2548.

Kennedy, M. B., M. K. Bennett, N. E. Erondu, and S. G. Miller (1987) Calcium/calmodulin-dependent protein kinases. In Calcium and Cell Function, Vol. VII, W. Y. Cheung, ed., pp. 61-107, Academic, New York.

Kennelly, P. J., A. M. Edelman, D. K. Blumenthal, and E. G. Krebs (1987) Rabbit skeletal muscle myosin light chain kinase. The calmodulin binding domain as a potential active site-directed inhibitory domain. J. Biol. Chem. 262: 11958-1 1963.

Kuret, J., and H. Schulman (1985) Mechanism of autophosphorylation of the multifunctional $\mathrm{Ca}^{2+} /$ calmodulin-dependent protein kinase. J. Biol. Chem. 260: 6427-6433.

Lai, Y., A. C. Nairn, and P. Greengard (1986) Autophosphorylation reversibly regulates the $\mathrm{Ca}^{2+} /$ calmodulin-dependence of $\mathrm{Ca}^{2+} / \mathrm{cal}-$ modulin-dependent protein kinase II. Proc. Natl. Acad. Sci. USA 83: 4253-4257.

LeVine, H., III, and N. E. Sahyoun (1987) Characterization of a soluble $\mathrm{Mr}-30000$ catalytic fragment of the neuronal calmodulin-dependent protein kinase II. Eur. J. Biochem. 168: 481-486. 
Lin, C. R., M. S. Kapiloff, S. Durgerian, K. Tatemoto, A. F. Russo, P. Hanson, H. Schulman, and M. G. Rosenfeld (1987) Molecular cloning of a brain-specific calcium/calmodulin-dependent protein kinase. Proc. Natl. Acad. Sci. USA 84: 5962-5966.

Lisman, J. E. (1985) A mechanism for memory storage insensitive to molecular turnover: A bistable autophosphorylating kinase. Proc. Natl. Acad. Sci. USA 82: 3055-3057.

Lisman, J. E., and M. A. Goldring (1988) Feasibility of long-term storage of graded information by the $\mathrm{Ca}^{2+} / \mathrm{calmodulin}$-dependent protein kinase molecules of the postsynaptic density. Proc. Natl. Acad. Sci. USA 85: 5320-5324.

Lou, L. L., S. J. Lloyd, and H. Schulman (1986) Activation of the multifunctional $\mathrm{Ca}^{2+} / \mathrm{calm}$ odulin-dependent protein kinase by autophosphorylation: ATP modulates production of an autonomous enzyme. Proc. Natl. Acad. Sci. USA 83: 9497 -9501.

Lukas, T. J., W. H. Burgess, F. G. Prendergast, W. Lau, and D. M. Watterson (1986) Calmodulin binding domains: Characterization of a phosphorylation and calmodulin binding site from myosin light chain kinase. Biochemistry 25: 1458-1464.

McGuinness, T. L., Y. Lai, P. Greengard, J. R. Woodgett, and P. Cohen (1983) A multifunctional calmodulin-dependent protein kinase. Similarities between skeletal muscle glycogen synthase kinase and a brain synapsin I kinase. FEBS Lett. 163: 329-334.

Miller, S. B., and M. B. Kennedy (1986) Regulation of brain type II $\mathrm{Ca}^{2+} /$ calmodulin-dependent protein kinase by autophosphorylation: $\mathrm{A} \mathrm{Ca}^{2+}$-triggcred molecular switch. Cell 44: 861-870.

Miller, S. B., B. L. Patton, and M. B. Kennedy (1988) Sequences of autophosphorylation sites in neuronal type II CaM kinase that controls $\mathrm{Ca}^{2+}$-independent activity. Neuron 1: 593-604.

Nestler, E. J., and P. Greengard (1982) Distribution of protein I and regulation of its state of phosphorylation in the rabbit superior cervical ganglion. J. Neurosci. 2: 1011-1023.

Nishizuka, Y. (1986) Studies and perspectives of protein kinase C. Science 233: 305-312.

O'Farrell, P. H. (1975) High resolution two-dimensional electrophoresis of proteins. J. Biol. Chem. 250: 4007-4021.

Payne, M. E., Y.-L. Fong, T. Ono, R. J. Colbran, B. F. Kemp, T. R. Soderling, and A. R. Means (1988) Calcium/calmodulin-dependent protein kinase II. Characterization of distinct calmodulin binding and inhibitory domains. J. Biol. Chem. 263: 7190-7195.

Rangel-Aldao, R., and O. M. Rosen (1976) Mechanism of self-phosphorylation of adenosine $3^{\prime}: 5^{\prime}$-monophosphate-dependent protein kinase from bovine cardiac muscle. J. Biol. Chem. 251: 7526-7529.

Saitoh, T., and J. H. Schwartz (1983) Serotonin alters the subcellular distribution of a Ca ${ }^{2+} /$ calmodulin-binding protein in neurons of Aplysia. Proc. Natl. Acad. Sci. USA 80: 6708-6712.
Saitoh, T., and J. H. Schwartz (1985) Phosphorylation-dependent subcellular translocation of a $\mathrm{Ca}^{2+} /$ calmodulin-dependent protein kinase produces an autonomous enzyme in Aplysia neurons. J. Cell Biol. 100: 835-842.

Schulman, H. (1984) Phosphorylation of microtubule-associated proteins by a $\mathrm{Ca}^{2+} /$ calmodulin-dependent protein kinase. J. Cell Biol. 99: 11-19.

Schulman, H. (1988) The multifunctional $\mathrm{Ca}^{2+} /$ calmodulin-dependent protein kinase. In Advances in Second Messenger and Phosphoprotein Research, vol. 22, pp. 39-112.

Schulman, H., and P. Greengard (1978) $\mathrm{Ca}^{2+}$-dependent protein phosphorylation system in membranes from various tissues and its activation by "calcium-dependent regulator." Proc. Natl. Acad. Sci. USA 75: 5432-5436.

Schulman, H., and L. L. Lou (1989) Multifunctional $\mathrm{Ca}^{2+} /$ calmodulindependent protein kinase: Domain structure and regulation. Trends in Biochem. Sci. 14: 62-66.

Schworer, C. M., R. J. Colbran, and T. R. Soderling (1986) Reversible generation of a $\mathrm{Ca}^{2+}$-independent form of $\mathrm{Ca}^{2+}$ (calmodulin)-dependent protein kinase II by an autophosphorylation mechanism. J. Biol. Chem. 261: 8581-8584.

Schworer, C. M., R. J. Colbran, J. R. Keefer, and T. R. Soderling (1988) $\mathrm{Ca}^{2+} /$ calmodulin-dependent protein kinase II. Identification of a regulatory autophosphorylation site adjacent to the inhibitory and calmodulin-binding domains. J. Biol. Chem. 263: 13486-13489.

Shenolikar, S., and T. S. Ingebritsen (1984) Protein (serine and threonine) phosphate phosphatases. Methods Enzymol. 107: 102-129.

Shields S. M., P. J. Vernon, and P. T. Kelly (1984) Autophosphorylation of calmodulin-kinase II in synaptic junctions modulates endogenous kinase activity. J. Neurochem. 43: 1599-1609.

Stull, J. T., M. H. Nunnally, and C. H. Michnoff (1986) Calciumdependent protein kinases. In The Enzymes, vol. 17, P. D. Boyer and E. G. Krebs, eds., pp. 113-165, Academic, New York.

Tachikawa, E., A. W. Tank, D. H. Weiner, W. F. Mosimann, N. Yanagihara, and N. Weiner (1987) Tyrosine hydroxylase is activated and phosphorylated on different sites in rat pheochromocytoma PC12 cells treated with phorbol ester and forskolin. J. Neurochem. 48: 13661376.

Thiel, G., A. J. Czernik, F. Gorelick, A. C. Nairn, and P. Greengard (1988) $\mathrm{Ca}^{2+} /$ calmodulin-dependent protein kinase II: Identification of threonine-286 as the autophosphorylation site in the $\alpha$ subunit associated with the generation of $\mathrm{Ca}^{2+}$-independent activity. Proc. Natl. Acad. Sci. USA 85: 6337-6341. 